\title{
Advances in Extracellular Matrix-Mimetic Hydrogels to Guide Stem Cell Fate
}

\author{
Ryan S. Stowers \\ Department of Mechanical Engineering, University of California, Santa Barbara, Santa Barbara, CA, USA
}

\section{Keywords}

Hydrogels · Stem cells · Extracellular matrix

\begin{abstract}
In the fields of regenerative medicine and tissue engineering, stem cells offer vast potential for treating or replacing diseased and damaged tissue. Much progress has been made in understanding stem cell biology, yielding protocols for directing stem cell differentiation toward the cell type of interest for a specific application. One particularly interesting and powerful signaling cue is the extracellular matrix (ECM) surrounding stem cells, a network of biopolymers that, along with cells, makes up what we define as a tissue. The composition, structure, biochemical features, and mechanical properties of the ECM are varied in different tissues and developmental stages, and serve to instruct stem cells toward a specific lineage. By understanding and recapitulating some of these ECM signaling cues through engineered ECM-mimicking hydrogels, stem cell fate can be directed in vitro. In this review, we will summarize recent advances in material systems to guide stem cell fate, highlighting innovative methods to capture ECM functionalities and how these material systems can be used to provide basic insight into stem cell biology or make progress toward therapeutic objectives.

(c) 2021 S. Karger AG, Basel
\end{abstract}

\author{
Introduction - Hydrogels to Mimic the Extracellular \\ Matrix
}

The extracellular matrix (ECM), like all materials, is governed by structure-function relationships. It is a highly regulated network of cell-secreted biopolymers that can be classified as proteins, proteoglycans, or glycosaminoglycans [Bosman and Stamenkovic, 2003]. The ECM serves at least 5 major roles; it provides structural support for cells, an interface for cellular attachment, topographical cues, binding sites and depots for morphogens, and has tissue-specific architecture and organization to facilitate tissue function [Hussey et al., 2018]. Notably, all 5 of these roles serve to regulate stem cell fate and behavior [Discher et al., 2009; Watt and Huck, 2013], and can be mimicked in vitro to varying extents using hydrogels [Tibbitt and Anseth, 2009; Kyburz and Anseth, 2015]. One important feature to consider regarding the ECM is that it both serves as a regulator of cell phenotype but is also secreted, degraded, remodeled and maintained by those very cells. This phenomenon where cells and the ECM interact with and influence one another is known as dynamic reciprocity [Bissell et al., 1982; Bissell and Aggeler, 1987; Xu et al., 2009] and is critically important to understanding how the ECM can direct dynamic developmental processes, and then serve a homeostatic role in 
maintaining proper tissue structure and function throughout life. Misregulation or loss of control of homeostasis can lead to severe pathological consequences [Lukashev and Werb, 1998].

Hydrogels are excellent choices for recapitulating the ECM in vitro for several reasons. First, they are highly hydrated, presenting a largely aqueous environment to cells, very similar to what cells experience in vivo. Additionally, the mechanical properties of hydrogels can be varied across the spectrum that is typical of soft tissues in the body, much more closely matching the microenvironmental conditions compared to supraphysiological tissue culture plastic or glass. ECM proteins can be derived and reconstituted to form hydrogels of similar composition to many cellular microenvironments. For example, Matrigel, a hydrogel-forming protein mixture derived from mouse tumor tissue and commonly used for 3D stem cell culture, is rich in laminin and collagen IV [Kleinman and Martin, 2005; Hughes et al., 2010], among the first ECM proteins secreted by the early blastocyst in development [Leivo et al., 1980; Zagris, 2001]. Finally, hydrogels can be formed from natural and synthetic polymers that are highly amenable to chemical modification and process engineering techniques that allow for control or modulation of their properties [Thiele et al., 2014; Caliari and Burdick, 2016].

\section{Mimicking Extracellular Matrix Mechanics to Control Stem Cell Fate}

The ECM presents not only biochemical signaling cues but also biophysical cues to direct and maintain cell fate. ECM mechanical properties vary dramatically depending on tissue type. For example, bone marrow and neuronal tissue are much softer and display more viscous character than mineralized bone matrix [Chaudhuri et al., 2020]. Cells are able to sense and respond to different ECM mechanics through a process known as mechanotransduction [Orr et al., 2006]. Briefly, cells bind to the and apply tension across integrins, activating downstream signaling pathways that alter gene expression and ultimately cell fate [Katsumi et al., 2004; Discher et al., 2005; Guilak et al., 2009; Schwartz, 2010]. A thorough description of mechanosensing and mechanotransduction are outside the scope of this review but are excellently covered in the provided citations.

The most well-studied mechanical property that regulates stem cell fate is stiffness, or elastic modulus. This property describes the deformation a material will un- dergo in response to an applied load, accounting for the sample geometry. Importantly, stiffness is time independent, and does not account for time-dependent behaviors often encountered in biological samples, which will be discussed in the subsequent sections. Tissue stiffness on the biological spectrum ranges from very soft: bone marrow, adipose tissue, neuronal tissue in the 10's-100's Pa range, to intermediate stiffness: like skeletal muscle around $20 \mathrm{kPa}$, up to very stiff bone: 10 s of GPa [Yoshikawa et al., 1999; Gefen and Margulies, 2004; Oftadeh et al., 2015]. Early work in stem cell mechanobiology utilized 2D hydrogels made from crosslinked polyacrylamide, where gel stiffness can be varied by changing the degree of crosslinks introduced during polymerization [Pelham and Wang, 1997; Wang and Pelham, 1998]. Polyacrylamide gels can be coated with cell adhesive peptide sequences or proteins to facilitate cell culture, similar to using tissue culture polystyrene but at physiologically relevant stiffness. Mesenchymal stem cells (MSCs) cultured on soft, intermediate, or stiff polyacrylamide substrates were found to differentiate into neural, muscle, and bone lineages, respectively [Engler et al., 2006]. This seminal work demonstrated that stem cell fate is regulated by mechanical properties, and provided a catalyst to the idea of engineering biomaterial platforms to not only support cells but to direct their fate. This principle was later corroborated and the underlying biological mechanisms elucidated using a number of different hydrogel platforms in 2D [Khatiwala et al., 2009; Yang et al., 2011] and later 3D culture [Huebsch et al., 2010] (Fig. 1a). Additionally, stiffness was shown to regulate differentiation of embryonic stem cells [Eroshenko et al., 2013; Przybyla et al., 2016], neural stem cells [Saha et al., 2008; Leipzig and Shoichet, 2009], and skeletal muscle stem cells [Gilbert et al., 2010]. Generally, the approach of increasing crosslinking density to increase hydrogel stiffness is a guiding principle for engineering hydrogel properties [Metters et al., 2000]. It should be noted that varying crosslink density for $3 \mathrm{D}$ cell culture applications necessarily alters other properties that can influence cell behavior and fate. For example, network pore size is also directly related to crosslink density [Metters et al., 2000]. Hydrogels with sufficiently small pores prevent cells from migrating. Thus, depending upon the application and the type of hydrogel selected, stiffness may not be tunable over the range of interest, without further modifying the hydrogel network to allow for remodeling, which we will discuss in later sections of this review.

In response to an applied load, many tissues undergo some degree of viscous flow and/or permanent deforma- 


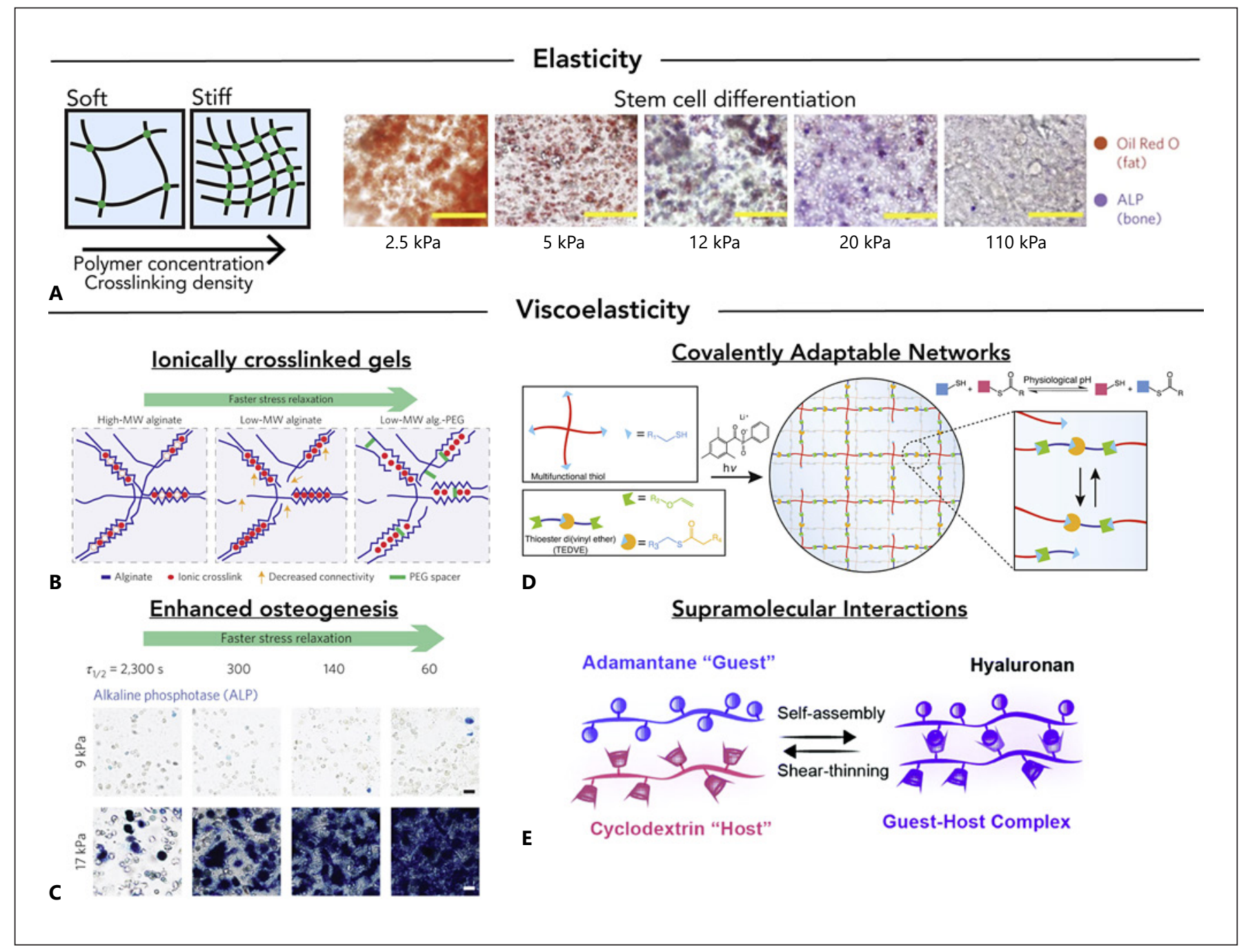

Fig. 1. Mimicking extracellular matrix mechanical properties to direct stem cell fate. A Matrix elasticity can be varied by changing the hydrogel crosslinking density or polymer concentration. Mesenchymal stem cell (MSC) differentiation is regulated by the elastic modulus of the surrounding hydrogel. B Viscoelasticity is exhibited by ionically crosslinked alginate hydrogels and can be tuned by altering the alginate chain length or PEGylating the alginate. C Faster relaxing alginate gels enhance MSC osteogenesis at constant elastic modulus (17 kPa). D Other strategies to generate hy-

tion [Chaudhuri et al., 2020]. These behaviors can be described as viscoelastic and plastic, or viscoplastic if the deformation is rate dependent, and are not typically exhibited by synthetic hydrogels covalently crosslinked in ideal networks like the early examples of polyacrylamide and polyethylene glycol (PEG) discussed previously. Hydrogels formed from reconstituted ECM proteins do exhibit time-dependent mechanics [Nam et al., 2016]. How-

Hydrogels to Guide Stem Cells drogels with viscoelastic behavior include covalently adaptable networks (D) and crosslinks formed by supramolecular interactions (E). A Reprinted with permission from Springer Nature [Huebsch et al., 2010]. Copyright 2010. B and C Reprinted with permission from Springer Nature [Chaudhuri et al., 2016]. Copyright 2016. D Reprinted from [Brown et al., 2018], Copyright [2018], with permission from Elsevier. E Reproduced from [Loebel et al., 2019a] with permission from The Royal Society of Chemistry.

ever, they generally have limited mechanical tunability, achieved by varying the protein concentration, which can also alter other influential properties such as cell adhesion ligand density and pore size [Zaman et al., 2006; Lang et al., 2015]. Thus, in order to better recapitulate the mechanical properties of the stem cell microenvironment, hydrogel networks must be engineered to exhibit timedependent mechanical properties. 
To determine what effect varying hydrogel viscoelasticity has on cell behavior and fate, polyacrylamide hydrogels were developed for 2D cell culture with variable viscosity and constant elasticity by modulating the ratio of the monomer to crosslinker [Cameron et al., 2011]. Interestingly, MSCs cultured on gels with higher loss modulus (viscosity) spread over larger areas, underwent increased proliferation and had increased differentiation potential toward several lineages. Viscoelastic polyacrylamide substrates that did not permit permanent deformation of surface adhesion ligands, on the other hand, led to a decrease in cell spreading, likely due to the inability of cells to cluster integrin ligands [Charrier et al., 2018]. Later, physically crosslinked alginate hydrogels with variable viscoelasticity were developed to assess the impact on stem cell differentiation in 3D culture [Chaudhuri et al., 2016] (Fig. 1b). The ionic nature of the crosslinks is inherently reversible, allowing for flow and remodeling of the polymer network in response to stress, known as stress relaxation. In these studies, shorter alginate chains were produced to lower the degree of chain entanglement in the polymer network, which provided less resistance to deformation and ultimately sped the stress relaxation rate. The stress relaxation rate could be further enhanced by conjugating short PEG chains to low molecular weight alginate to achieve very fast relaxing hydrogels. MSCs were found to undergo enhanced osteogenesis when cultured in fast relaxing alginate gels with an elastic modulus of $17 \mathrm{kPa}$ [Chaudhuri et al., 2016] (Fig. 1c). Cells were able to increasingly cluster integrins in fast relaxing $3 \mathrm{D}$ hydrogels due to the higher mobility of the polymer chains, which altered the cytoskeletal tension present in the cell. In later studies using this $3 \mathrm{D}$ alginate platform, it was shown that the hydrogel imposes resistance to cell volume expansion that is inversely related to the rate of stress relaxation [Lee et al., 2017, 2019]. Fast relaxing gels allowed for rapid and dramatic increases in cell volume, mediated by the ion channel TRPV4, that ultimately led to enhanced osteogenesis [Lee et al., 2019]. Very recently, the same researchers showed that conjugating increasing amounts of PEG onto alginate serves to increase the stress relaxation rate, presenting a simple and broadly accessible platform for tuning viscoelasticity in 3D cell culture systems [Nam et al., 2019]. These studies provided a strong foundation for studying stem cell mechanobiology in response to viscoelasticity and motivated the development of a number of other strategies to incorporate viscoelastic elements into hydrogels.

Many common hydrogel platforms are formed from covalently crosslinked synthetic polymers, which are typ- ically purely elastic and do not relax stress over time. To introduce viscoelasticity into these synthetic gels, several dynamic covalent crosslinking chemistries have been developed and adapted to hydrogels for 3D cell culture. Reversible hydrazone crosslinks were used to form PEG hydrogels with tunable elastic modulus and stress relaxation rate [McKinnon et al., 2014a, b]. Hydrazone dynamics can be tuned by introducing different species, e.g., aliphatic vs. aromatic aldehydes, which have different kinetics due to the difference in hydrolytic potential [Richardson et al., 2020]. Anseth and colleagues have developed several PEG-based hydrogel systems with covalent adaptable networks that exhibit viscoelasticity through crosslinks based on boronate [Tang et al., 2018], thio-ester exchange [Brown et al., 2018], and allyl sulfide [Tang et al., 2018; Marozas et al., 2019] (Fig. 1d). These hydrogels have been used to examine cellular response in dynamic networks for a variety of biological applications, including the generation and maturation of intestinal organoids [Hushka et al., 2020; Yavitt et al., 2020].

The examples described above using PEG, polyacrylamide, and alginate rely on polymer networks that are not naturally occurring in the human body. While these systems are tremendously useful for many applications, there are occasions when utilizing naturally occurring biopolymers would be beneficial. One such biopolymer, hyaluronic acid (HA) is an abundant component of the extracellular matrix, particularly in cartilage, skin, and nervous tissue. HA is a glycosaminoglycan (GAG), however it is distinct from other GAGs in that it is non-sulfated and is synthesized in the body at very high molecular weights, often in excess of one million daltons. HA has been used as an in vitro hydrogel-forming material for several decades, often by modifying the HA polymer chains with crosslinker groups to form a covalently crosslinked network [Burdick and Prestwich, 2011; Highley et al., 2016]. Similar to the examples of polyacrylamide and PEG described above, the stiffness of HA hydrogels can be varied by altering the degree of crosslinking [Park et al., 2003; Jeon et al., 2007]. Burdick and colleagues developed an HA hydrogel network exhibiting viscoelasticity by incorporating a guest-host crosslinking chemistry between cyclodextrin and adamantane [Rodell et al., 2013, 2015] (Fig. 1e). These hydrogels rapidly relax stress, and can even be injected or used for bioprinting applications owing to their shear thinning character [Highley et al., 2015; Ouyang et al., 2016; Loebel et al., 2017]. The same group has also developed viscoelastic HA-based hydrogels utilizing hydrazone crosslinks and demonstrated their utility for 3D cell culture [Wang et al., 2018]. HA 
modified with aldehyde functional groups was crosslinked with hydrazine-modified elastin-like proteins to yield an injectable hydrogel for MSC delivery, and it was shown that cells maintained their multipotent differentiation capacity after injection [Wang et al., 2017].

In many tissues, cells are presented with fibrillar protein network surrounded by a mesh of GAGs like HA. To more faithfully recapitulate this environment, hydrazone-crosslinked HA networks, in which stress relaxation can be tuned through a number of parameters, were formed in combination with collagen I networks to generate an interpenetrating network [Lou et al., 2018]. These hydrogel networks were shown to have stress relaxation rates that could be tuned over the physiological spectrum by modulating the HA molecular weight, the aldehyde group used for hydrazone crosslinking, or the concentration of HA in the gel. Intriguingly, in fast stress-relaxing networks, MSCs were able to remodel and realign the collagen fibers surrounding them and underwent significantly more spreading compared to control HA-networks that could not relax stress. Key markers of early focal adhesion maturation were observed only for cells cultured in environments that were both fibrillar and stress relaxing, emphasizing the necessity of recapitulating both the mechanical and structural aspects of the ECM.

Another important mechanical consideration at play in the extracellular matrix is viscoplasticity or permanent deformation of the ECM architecture due to breaking of weak bonds and entanglements in the fiber networks. When the network architecture of weakly bonded fibers is realigned, and new weak bonds form, the network is permanently deformed and will not recover its prior arrangement, as in the fiber remodeling described above [Lou et al., 2018]. This is observed on the cellular scale during fiber alignment and cellular migration, when fiber tracks develop that facilitate cancer cell invasion, for example. Hydrogels made from ECM proteins, such as Matrigel, collagen I, or fibrin, exhibit viscoplasticity. Physically crosslinked hydrogels such as alginate can also undergo viscoplastic deformation. Recently, interpenetrating networks of alginate and Matrigel were used to create a suite of hydrogels with varying degrees of viscoplasticity, with independent control of stiffness and constant stress relaxation rate [Wisdom et al., 2018; Chang et al., 2020]. To date, the viscoplasticity of stem cell niches is not well characterized, and thus it is not clear what design targets should be pursued by hydrogel engineers to accurately recapitulate this parameter.

There is emerging evidence that matrix confinement can impact cell phenotype, behavior and differentiation by restricting cell volume. On $2 \mathrm{D}$ substrates, it has been shown that cells increasingly spread on stiffer surfaces, resulting in a decrease in cell volume [Guo et al., 2017; Perez Gonzalez et al., 2018; Xie et al., 2018]. The decrease in cell volume associated with stiff substrates resulted from water efflux from the cell and was found to be mediated by actomyosin contractility and ion channels. Notably, MSC differentiation was also dependent on cell volume. Using hyperosmotic solutions to compress cells and reduce intracellular volume, MSCs underwent enhanced osteogenic differentiation even on very soft $(0.2 \mathrm{kPa})$ substrates [Guo et al., 2017]. The environmental restrictions imposed on a cell in a 3D matrix would likely be very different from that of a large, flat 2D substrate. Indeed, it has been shown that cell spreading, volume, and YAP/TAZ nuclear translocation in response to matrix stiffness follows opposite trends on $2 \mathrm{D}$ substrates compared to $3 \mathrm{D}$ matrices [Caliari et al., 2016]. As discussed earlier in this review, MSCs encapsulated in 3D alginate gels undergo enhanced osteogenesis when they can expand their volume through relaxation of matrix stress [Lee et al., 2019]. When volume expansion was restricted by hyperosmotic conditions, osteogenesis was significantly reduced, in contrast to prior 2D studies [Guo et al., 2017]. Adiposederived stem cells encapsulated in $3 \mathrm{D}$ matrices were found to have increased cell volume in softer regions of a stiffness gradient [Major et al., 2019]. Interestingly, the osteogenic regulator RUNX2 was increasingly expressed in soft regions of the gel, where cell volume was highest, and expression of the adipogenic marker PPAR $\gamma$ was highest in stiffer regions of the gel, where volume expansion was restricted. It is evident that the degree of matrix confinement plays a prominent role in regulating stem cell differentiation by controlling cell volume. Much work remains to unravel the regulatory pathway by which cells sense their matrix and respond with volume changes, but this represents another avenue to guide stem cell fate, by encapsulating cells in permissive or restrictive environments or printing microniches with defined volumes [Bao et al., 2019].

\section{Mimicking Extracellular Matrix Structure and Biochemistry to Control Stem Cell Fate}

The structure of the ECM can also provide instruction to stem cells to regulate their differentiation or expansion. This is not surprising since stem cells must generate all the tissues of the body and reside in distinct niches in adults to maintain and regenerate mature tissues. The 
stem cell niches can have many distinct features, such as ECM biopolymer composition, architectural or topological cues, varieties of cell adhesion molecules, and sites for tethering of morphogens that all combine to regulate cell fate [Gattazzo et al., 2014]. Often, many ECM molecules fulfill multiple functions. For example, collagens serve as a structural scaffold to physically support cells, but also provide cell adhesion domains to facilitate cell attachment and migration [Heino, 2007; Bielajew et al., 2020]. Laminins are a primary component of the basement membrane protein mesh that supports and provides adhesion sites for epithelia and also have been shown to possess binding sites for morphogens [Miner and Yurchenco, 2004; Ishihara et al., 2018]. These functions of the stem cell ECM should be considered when developing artificial hydrogels for in vitro stem cell culture.

The use of reconstituted ECM proteins to form hydrogels nicely mimics several of these aspects. The proteins are naturally occurring, thus simulating similar compositions for at least some stem cell niches. Proteins like collagen I and fibrin form similar fiber networks in vitro as are observed in vivo, and reconstituted basement membrane (Matrigel) forms a similar mesh as those found in epithelial basal laminas. The peptide sequences displayed on these proteins are recognizable to the cells, and these proteins maintain their ability to sequester morphogens. However, in some cases, the advantages of ECM protein gels are overridden by limitations, such as limited mechanical tunability, rapid degradation, batch-to-batch product variation, immunogenicity, supply chain issues, and other concerns described in detail elsewhere [Caliari and Burdick, 2016; Aisenbrey and Murphy, 2020]. For those reasons, hydrogel engineering approaches have been applied to mimic ECM structural and biochemical features.

One common approach to modify biomaterials to facilitate cell adhesion is to conjugate adhesion proteins, such as fibronectin, laminin, and perlecan, or the specific peptide sequences bound by cells in those proteins, such as RGD in fibronectin or IKVAV in laminin, directly to the hydrogel network. In 3D hydrogels, conjugation of cell binding domains allows for viability of anchoragedependent cells [Wang et al., 2010]. Recently, synthetic hydrogels were designed to support intestinal stem cell (ISC) survival and proliferation by enriching the hydrogel network with a cell adhesion molecule, either laminin, fibronectin, collagen IV, hyaluronic acid, or perlecan [Gjorevski et al., 2016]. Surprisingly, all of these supported colony formation from ISCs, and an even more mini- malist design, incorporation of only the RGD-domain, still supported high levels of ISC colonies. Similar results were observed for PEG hydrogels modified with RGD to support human intestinal organoid development from ESC-derived ISCs [Cruz-Acuña et al., 2017, 2018]. PEG hydrogels were used in another study to screen conditions that would yield high levels of reprogramming of somatic cells to iPSCs [Caiazzo et al., 2016]. While many proteins and peptides motifs facilitated some degree of reprogramming in 3D hydrogels, laminin and EpCam decorated hydrogels most enhanced reprogramming efficiency.

One critical distinction from naturally occurring ECM and the structure of many hydrogels used for in vitro cell culture is the fibrillar character present in many tissues. The architecture of this network varies substantially across different tissues, for example collagen fibers are highly aligned and organized in tendons [Kannus, 2000]. However, many conventional hydrogels present an amorphous, nanoporous network that does not closely resemble the micron-scale fibrillar environment commonly found in many stem cell niches [Prince and Kumacheva, 2019]. Even the use of reconstituted ECM proteins, like collagen I or Matrigel, does not fully recapitulate the native architecture and organization, and is exceedingly difficult to control a priori, and presents the lack of mechanical tunability discussed previously. For these reasons, much effort has been devoted to designing engineered fibrillar hydrogels [Prince and Kumacheva, 2019]. Electrospinning polymers offers a facile method to generate fibrous networks resembling the ECM network, and even allows for control of fiber orientation to produce aligned scaffolds [Davidson et al., 2020a, b]. Electrospun dextran was used to demonstrate that MSCs in a fibrillar environment can dynamically realign the fiber network to cluster adhesive ligands and form focal adhesions on soft fiber matrices compared to a stiffer matrix [Baker et al., 2015] (Fig. 2c). In an interpenetrating network of collagen I and dynamically crosslinked HA that exhibited fast stress relaxation rates, MSCs could remodel the fiber network and developed focal adhesions [Lou et al., 2018]. Interestingly, in gels that either did not exhibit stress relaxation or did not present the fibrillar collagen network, fiber remodeling and focal adhesion formation were limited, emphasizing the importance of recapitulating both the architectural and mechanical cues to elicit the appropriate signaling response from stem cells. Nanofibrillar cellulose hydrogels have also been developed to maintain pluripotency in hPSCs and drive embryoid body formation in a 3D environment [Lou et al., 2013]. 
Fig. 2. Mimicking ECM biochemical and structural properties to influence stem cells. A Engineered proteins displaying adhesion and degradation sites can be used to form hydrogels with variable degradability. Neural progenitor cells maintain stemness only in highly degradable gels, independent of stiffness. B Simultaneous 3D photopatterning of growth factors $(\mathrm{SHH}-\mathrm{red}$, CNTF - green). C Engineered fibrillar hydrogel network reproduces the network topology and mechanics of many fibrillar ECM environments. a Reprinted by permission from Springer Nature [Madl et al., 2017], Copyright 2017. b Reprinted by permission from Springer Nature [Wylie et al., 2011], Copyright 2011. c Reprinted by permission from Springer Nature [Baker et al., 2015], Copyright 2015.

Hydrogels to Guide Stem Cells
Tunable Degradability

Elastin-like protein (ELP):

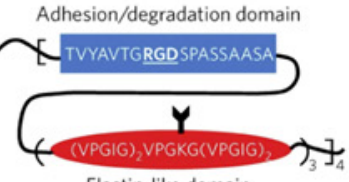

Elastin-like domain
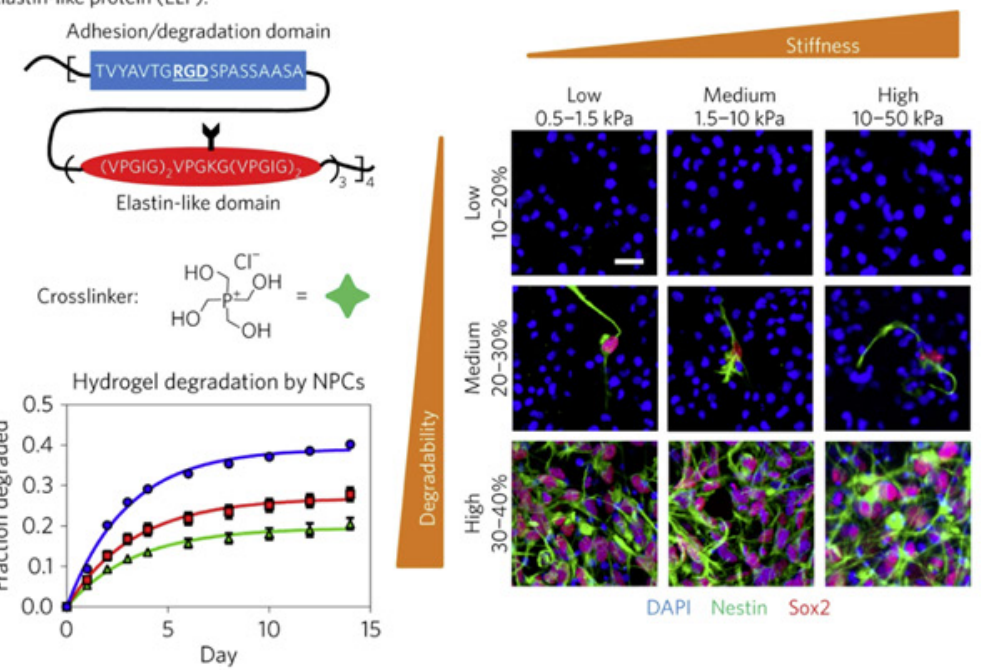

A

Patterned Growth Factors
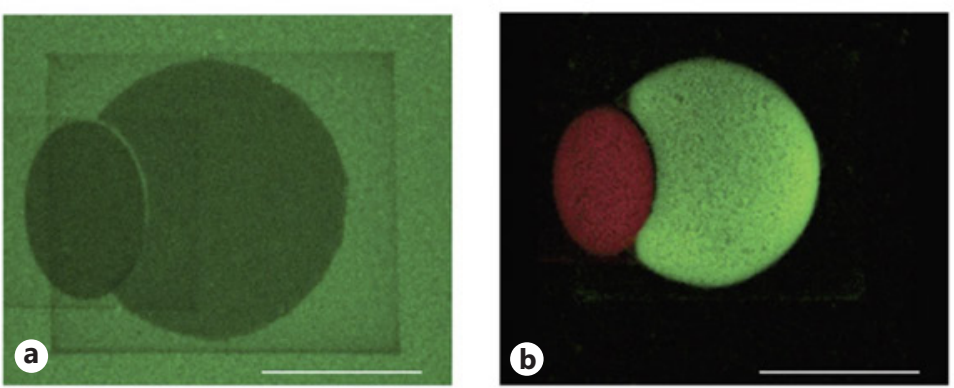

B
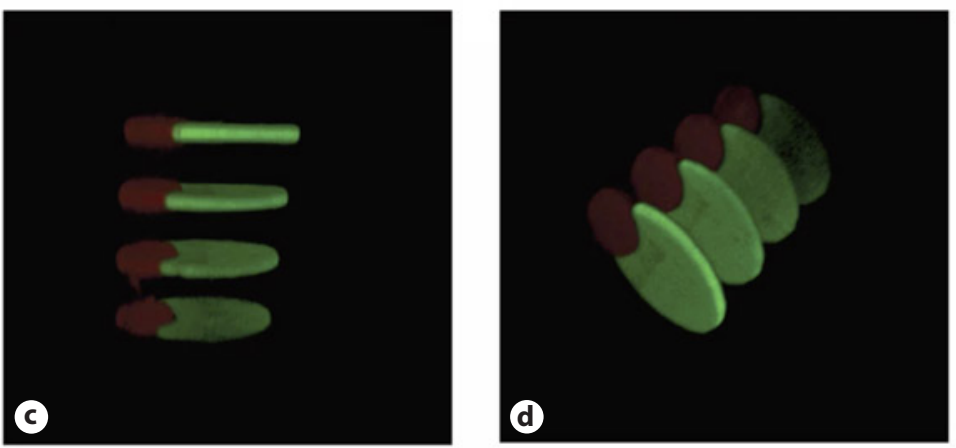

Engineered Fibrillar Hydrogels
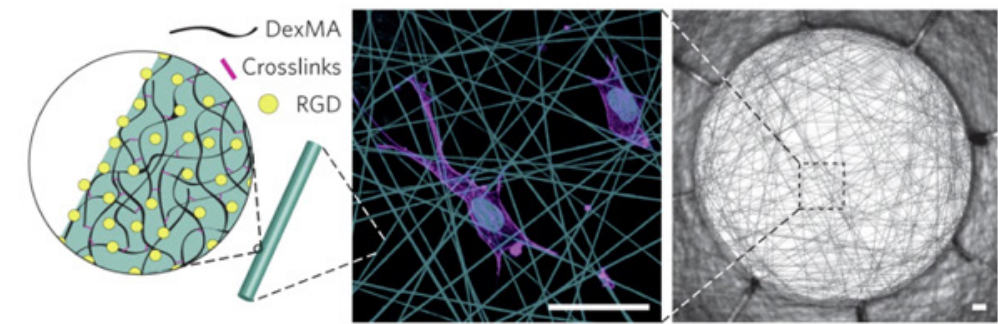
Another critical role that the ECM plays in guiding stem cell fate is to sequester morphogens in the extracellular space and present them for nearby cells [Hynes, 2009; Rozario and DeSimone, 2010]. Glycoproteins, such as fibronectin, laminins, and tenascin $\mathrm{C}$ primarily serve this function, often through heparin binding domains that promote growth factor binding [Pantoliano et al., 1994; Thompson et al., 1994]. For example, fibronectin has been shown to bind vascular endothelial growth factor (VEGF), transforming growth factor $ß 1$ (TGF-ß1), platelet-derived growth factor (PDGF), bone morphogenetic protein (BMP) 2 and 7, brain-derived neutrophic factor, hepatocyte growth factor, several insulin-like growth factor binding proteins, and several fibroblast growth factors (FGF) [Martino and Hubbell, 2010]. Similarly, heparin binding domains exist within laminins, allowing for binding of many growth factors with varying specificity based on laminin isoform [Ishihara et al., 2018]. For an excellent review on how ECM morphogen sequestration effects stem cells in development and strategies for incorporation in biomaterials, see Hettiaratchi et al. [2016]. Here, we will focus specifically on the use of morphogen-matrix interactions to direct stem cell fate.

Early work to couple growth factors to hydrogel matrices utilized reactive PEG linkers that could be reacted on one end with the growth factor of interest and then conjugated to a collagen matrix [Bentz et al., 1998; Koch et al., 2006]. A light-triggered strategy was later developed to allow for conjugation of FGF2 and TGF-ß1 to collagen, which promoted chondrogenic differentiation of MSCs [Bertolo et al., 2015]. TGF-ß1 was also coupled to a fibrin network using heterobifunctional PEG linkers to enhance pericyte differentiation in a neovascularization model from a population of human MSCs [Stowers et al., 2013]. Covalent conjugation directly to the growth factor of interest can alter the reactivity or potency of the morphogen. To mimic the natural sequestration and presentation, and minimize the loss of function of the bound morphogens, heparin has been directly incorporated into collagen networks through both covalent attachment or physical entrapment within the polymer network [Wissink et al., 2000; Johnson et al., 2011; Knaack et al., 2014]. These materials can be pre-loaded with GFs or loaded during the course of cell culture to retain GFs for longer time periods. Notably, both methods of incorporation were shown to improve bioactivity compared to chemical modification of the GF directly. Heparinization of synthetic hydrogel networks has been demonstrated to introduce more natural GF sequestration and presentation. Methacrylated heparin was co-polymerized with PEG and shown to bind GFs to enhance hMSC survival, proliferation and osteogenesis [Benoit and Anseth, 2005]. Further studies demonstrated the role of incorporated heparin in sequestering cell-secreted factors, where osteogenic gene expression and differentiation were substantially increased compared to non-heparinized hydrogels [Benoit et al., 2007]. Heparin has also been incorporated into HA gels, where it was shown to bind TGF- $B 1$ and significantly enhance cardiac progenitor cell differentiation and neovascularization [Jha et al., 2015a, b]. While heparin has been the most popular ECM GAG to incorporate into hydrogel matrices, others, such as chondroitin sulfate and heparan sulfate have been used for similar means [Varghese et al., 2008]. Additionally, domains known to associate with morphogens have been identified from ECM GAGs and have been synthesized and tethered within hydrogels. In one prominent example, fibronectin fragments responsible for growth factor binding (the 12th to 14th type III repeats) and integrin binding (the 9th and 10th type III repeats) were recombinantly expressed together and covalently attached to a fibrin hydrogel [Martino et al., 2011]. PDGF, VEGF, and BMP were shown to bind to the matrix and MSC osteogenic gene expression was enhanced, even compared to incorporation of full-length fibronectin. Importantly, MSC osteogenic expression was not significantly elevated over control conditions when the GF binding domain along was incorporated, highlighting the synergy of GF and adhesion signaling and underscoring the importance of orthogonal strategies of mimicking the ECM. Heparin binding domains were also identified within laminin isoforms, with variable GF affinity [Ishihara et al., 2018]. These domains could similarly be incorporated into fibrin matrices to promote VEGF and PDGF-BB binding. Given the broad spectrum of GFs bound by laminins and the specificity of certain isoforms, there is potential to synthesize domains with particular affinity for a GF of choice for use in directing stem cell fate based on specific applications.

\section{Mimicking Extracellular Matrix Dynamics to Control Stem Cell Fate}

Thus far, we have discussed methods to produce hydrogels that recapitulate particular features of stem cell niches within the ECM. It is important to recognize that, in many contexts, the ECM is highly dynamic [Gattazzo et al., 2014]. Cells continually remodel their microenvironment, and even during periods of homeostasis, ECM 
proteins are being degraded and secreted. During events like development and wound healing, the ECM undergoes substantial changes over time in a combination of composition, structure, mechanical properties, and biochemical cues which, as we have already discussed, have a dramatic impact on stem cell fate. Thus, the ideal hydrogel platform to study stem cell interactions with the microenvironment would allow for dynamic changes in the ECM properties of interest.

Early efforts aimed at designing dynamic hydrogels focused on incorporating degradable linkers into the hydrogel network. Hydrolysis, the cleavage of chemical bonds by the presence of water, can be utilized to facilitate degradation of hydrogels at a predictable rate. For example, hydrolytically-cleavable poly-L-lactic acid was co-polymerized with hydrophilic but non-degradable PEG to form 3D hydrogels [Bryant and Anseth, 2003]. Similarly, hydrolytically cleavable ester bonds were incorporated into crosslinks in a PEG hydrogel [Zustiak and Leach, 2010]. By tuning the initial crosslinker molecular weight, functionality, and total polymer density, the degradation rate by hydrolysis and associated mechanical properties could be accurately predicted over time. To permit cellmediated degradation, a very common strategy is to incorporate enzymatically cleavable linkers into hydrogels networks. Hubbell and colleagues demonstrated that matrix metalloprotease-specific crosslinks could allow for cell-triggered degradation and cell migration in 3D hydrogels [Lutolf et al., 2003a, b]. One advantage of this approach compared to hydrolysis is that degradation only occurs around cells secreting active enzymes, recapitulating some aspects of degradation-mediated migration. Hydrolysis and enzymatic degradation have been used in tandem to tailor the degradation rate of HA-based hydrogels for tissue engineering applications. HA, which can be degraded by the addition of exogeneous hyaluronidase, was crosslinked with hydrolytically cleavable methylacrylated caprolactone [Chung et al., 2009]. MSCs encapsulated within degradable gels had enhanced expression of cartilage-specific ECM genes, secreted more collagen II and aggrecan, and had superior mechanical properties compared to non-degradable controls. Thus, early efforts established the importance of matching not only ECM mechanical, structural, and compositional cues, but also native ECM timescales in terms of cellular remodeling. Indeed, MSCs encapsulated in stiff ( $>20 \mathrm{kPa}$ ) covalently crosslinked HA gels, matrix metalloprotease-degradable crosslinks were necessary to facilitate substantial osteogenesis [Khetan et al., 2013]. Cells remained rounded and favored adipogenesis regardless of stiffness unless de-

Hydrogels to Guide Stem Cells gradable crosslinks were present. Recently, it was shown that neural progenitor cell stemness could be maintained in $3 \mathrm{D}$ cultures by providing degradable crosslinkers, which permitted matrix remodeling and subsequent cellcell signaling [Madl et al., 2017] (Fig. 2a). It should be noted that the degradation of crosslinks within the hydrogel network will necessarily decrease the crosslinking density, altering the parameters associated with it that we described previously, including decreasing the elastic modulus. These mechanical changes associated with cellmediated degradation would be experienced locally by cells, and if the network connectivity was sufficiently degraded, it would result in dissolution of the gel [Zustiak and Leach, 2010].

To provide more exacting control of degradation, photoreactive elements have been incorporated into hydrogels. Using light-based reactions provides exquisite spatiotemporal precision, allowing for control of when, where, and to what extent reactions are carried out. PEG hydrogels with photodegradable units incorporated in the polymer network could be softened over time or at particular locations within the gel, and permitted cell migration along degraded tracks with 3D control [Kloxin et al., 2009]. This seminal paper showed for the first time, user-directed, real-time control of matrix mechanical properties in the presence of encapsulated cells. Much effort has been devoted to developing other methods for dynamic tuning of hydrogel mechanics, particularly the ability to stiffen materials over time, as stiffening is observed in tissue development and also several fibrotic diseases [Liu et al., 2010; Rozario and DeSimone, 2010; Lu et al., 2012]. As one example, developing myocardium was measured to increase in elastic modulus from less than 1-9kPa over the course of tissue maturation [Young and Engler, 2011]. To mimic this temporal stiffening, thiolated-HA was crosslinked by the addition of PEG-diacrylate. The kinetics of this reaction could be tuned to alter the time scale of stiffening, and a suitable combination was found that could mimic the stiffening timeline of the developing myocardium, which led to enhanced cardiomyocyte maturation [Young and Engler, 2011]. To provide researchers control of stiffening in real-time, a lighttriggered stiffening strategy was developed in a 2D HAbased hydrogel system, where a secondary crosslinking reaction increased the elastic modulus from 3 to $30 \mathrm{kPa}$ [Guvendiren and Burdick, 2012]. Similarly, PEG gels could be stiffened by swelling in additional PEG-thiol, PEG-norbornene, and a photoinitiator, and exposing the gel to UV light to crosslink a secondary network within the original hydrogel network [Mabry et al., 2015]. An 
approach to modulating stiffness in non-covalently crosslinked hydrogels was developed for calcium-crosslinked alginate gels [Stowers et al., 2015]. Light-responsive liposomes were loaded with calcium or calcium chelators and distributed throughout 3D alginate gels. Upon exposure to near infrared light, the entrapped molecules were released, and either formed additional crosslinks to stiffen the gel (release of calcium) or chelated calcium from within the alginate network to soften the gels (release of chelators). This system demonstrated the ability to either stiffen or soften 3D gels using the same platform, and employed near infrared light, which penetrates tissue more deeply than UV wavelengths [Rapp and DeForest, 2020], allowing for transdermal applications [Allen et al., 2020]. Rosales et al. [2017] made further progress by developing HA hydrogels that could be crosslinked at an initially high elastic modulus $(15 \mathrm{kPa})$, then softened by photodegradation of o-nitrobenzyl crosslinks $(3.5 \mathrm{kPa})$, and finally re-stiffened via radical photopolymerization of methacrylate groups on HA to elastic moduli greater than the initial value $(28 \mathrm{kPa})$ [Rosales et al., 2017]. Recent work inspired by optogenetics allowed for reversible and repeatable modulation of elastic modulus by incorporating cyanobacterial phytochrome 1 (Cph1) into PEG hydrogels [Hörner et al., 2019] (Fig. 3d). Dimerization of the Cph1 proteins, which serve as additional hydrogel crosslinks, could be precisely controlled by the wavelength and intensity of light. The gel mechanics could be rapidly changed to control MSC spreading, mechanosignaling, and gene expression profiles. Much of the prior work has focused on the ability to modulate stiffness over time, but as discussed previously, the viscoelasticity of hydrogels can also substantially affect cell fate. In order to tune viscoelasticity over time, a lightmediated reaction was developed using HA crosslinked with a combination or covalent bonds and supramolecular interactions (B-cyclodextrin-adamantane) [Hui et al., 2019]. Notably, this platform allows for secondary phototuning to simultaneously increase the elastic modulus and decrease the stress relaxing capacity of the gel, with spatiotemporal precision afforded by light-triggered reactions. The suite of platforms and degree of spatiotemporal control of hydrogel crosslinking are rapidly progressing, providing an expanding toolbox for interrogating the mechanical dynamics driving stem cell differentiation (Fig. 3).

Thus far, most of strategies discussed here for dynamic modulation of mechanical properties rely on increasing or decreasing the number of crosslinks in a hydrogel network. An orthogonal strategy is to modulate the phys- ical properties of the polymer chains themselves, such as the persistence length (rigidity of the polymer chain) or the contour length (total length of the polymer chain) to alter the resulting network mechanics. Azobenzenes undergo a shift from a trans-isomer to a cis-isomer upon exposure to UV light, and convert back in visible wavelengths. Azobenzenes were incorporated into a peptide sequence used to crosslink PEG hydrogels, and upon exposure to light the conformational shift altered the contour length of the polymer chain between crosslinks to either stiffen or soften the gel, depending on the wavelength selected [Rosales et al., 2015]. Notably, this approach does not rely on the addition of photoinitiators and importantly, allows for multiple rounds of cyclical tuning (e.g., stiffen and then soften). Proteins that undergo a conformational change in response to a stimulus have recently been incorporated into hydrogel crosslink segments along with their binding partners to achieve similar results [Liu et al., 2018]. Upon exposure to the stimulus, the protein-binding partner interaction is promoted, which shortens the chain length between crosslinks (i.e., stiffens the gel). Removal of the stimulus promotes unbinding and softening of the gel, again demonstrating the ability to cyclically tune mechanics by altering crosslinker length. These methodologies shorten the distance between crosslinks to increase crosslink density and thus stiffness, rather than introducing additional crosslinks as in prior examples.

A prominent example of the utility of dynamic hydrogels is the discovery of mechanical memory in mesenchymal stem cells. Anseth and colleagues observed that MSCs became osteogenically-biased with increasing culture time on supraphysiologically stiff tissue culture polystyrene [Yang et al., 2014] (Fig. 3a). MSCs were cultured on initially stiff $(10 \mathrm{kPa}) 2 \mathrm{D}$ PEG gels that were softened to $2 \mathrm{kPa}$ after various time periods. The authors found that for short time periods on stiff substrates, the MSCs maintained their multipotent differentiation capacity, but after a sufficiently long time, the cells were irreversibly biased toward osteogenesis by activation of transcriptional regulatory pathways through YAP/TAZ and RUNX2. Independent studies yielded a similar observation for hydrogels that were stiffened at various timepoints. MSCs were more likely to undergo adipogenic differentiation and less likely to undergo osteogenic differentiation when stiffening occurred later in the experiment (i.e., when cells were cultured on soft substrates for longer) [Guvendiren and Burdick, 2012]. The molecular basis for mechanical memory is still be investigated, but recent evidence points toward an epigenetic foundation. Micro- 


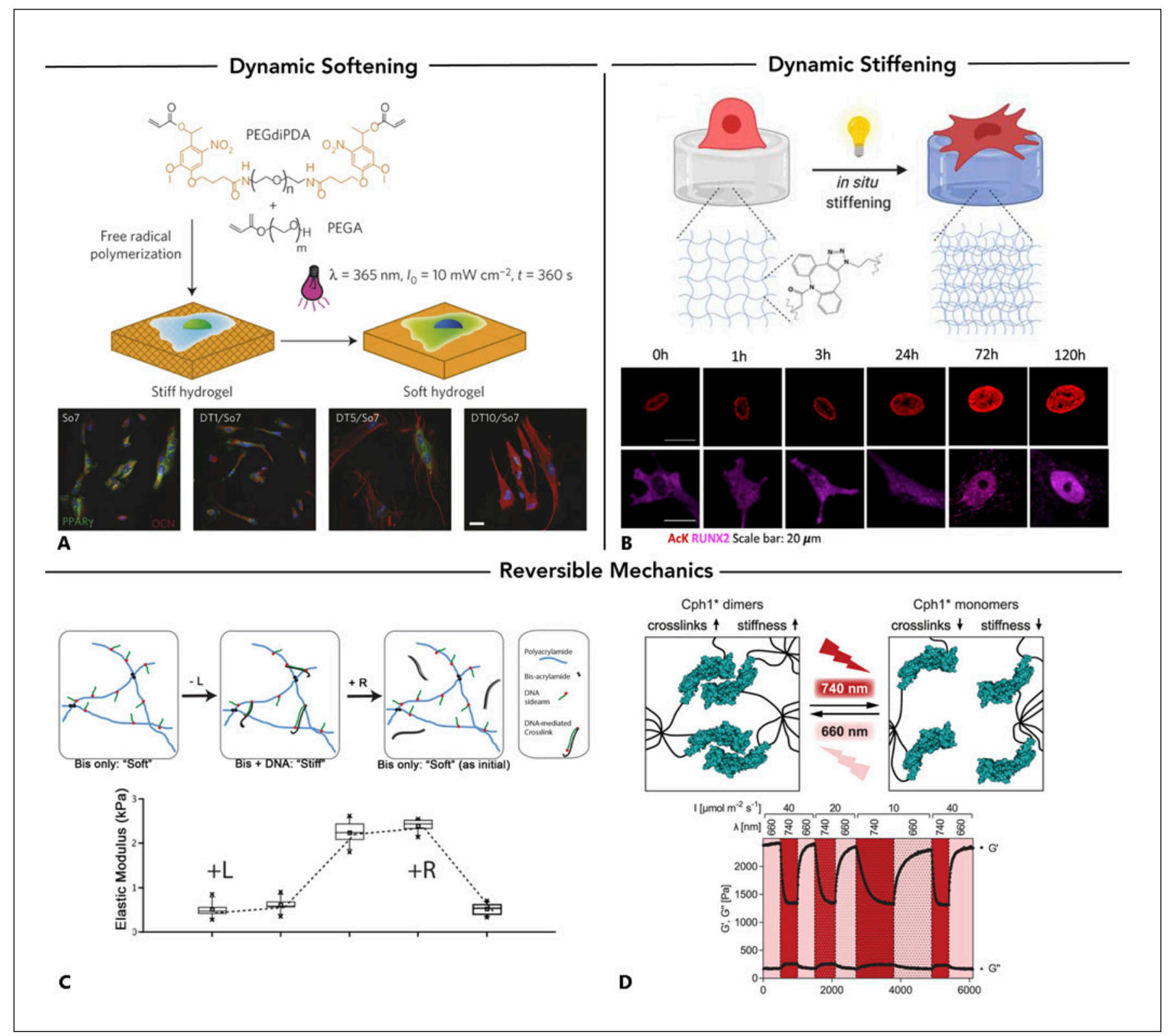

Fig. 3. Mimicking ECM dynamic mechanical properties with hydrogels. A Photodegradable crosslinks in PEG hydrogels to soften gels over time. This platform was used to demonstrate the presence of mechanical memory in MSCs. B Hydrogel stiffening via lighttriggered secondary crosslinking. Stiffening drove changes in histone acetylation and RUNX2 localization. C, D Hydrogel mechanical properties can be reversibly tuned using DNA-mediated crosslinks (C) or wavelength-dependent optoprotein dimerization (D).
A Reprinted by permission from Springer Nature [Yang et al., 2014], Copyright 2014. B Reproduced with permission under the terms of the CC-BY-NC-ND-4.0 license [Killaars et al., 2020]. Copyright the Authors 2020, published by PNAS. C Reproduced with permission [Rammensee et al., 2017], Copyright 2016, John Wiley and Sons. D Reproduced with permission [Hörner et al., 2019], Copyright 2019, John Wiley and Sons.
RNA miR-21 was shown to increase during culture of MSCs on stiff substrates, and knockdown of miR-21 was found to erase mechanical memory [Li CX et al., 2017]. The Anseth group, in recent studies, has shown that his-

Hydrogels to Guide Stem Cells tone acetylation (HAc) levels increase for MSCs cultured on stiff substrates, while histone deacetylases (HDACs) are downregulated [Killaars et al., 2019]. Intriguingly, when stiff gels are softened after short time periods, HAc 
levels decrease, but become irreversible after longer time periods on stiff gels, mirroring the differentiation capacity. Conversely, stiffening an initially soft gel produces the opposite effect, histone aceylation levels increase from a low baseline while HDAC activity and expression is decreased [Killaars et al., 2020] (Fig. 3b). While these studies and other have begun to shine light on the interplay between matrix mechanical properties and epigenetics [ $\mathrm{Li}$ Y et al., 2017; Stowers et al., 2019; Nemec and Kilian, 2020; Heo et al., 2015, 2016a, b], much work remains to untangle the complex interactions at play. Achieving a firm understanding of how to design substrates or 3D environments to maintain stem cell potency or drive reprogramming of cells to multipotency or pluripotency remains a key challenge in the field of mechanobiology. Dynamically tunable hydrogels may provide an avenue to reprogram, expand, and then direct differentiation of stem cells in a user-controlled fashion, but this approach requires further biomaterials development and greater knowledge of cell-material interactions.

Just as ECM mechanical properties change over time during physiological processes and pathological events, the structural and molecular cues within the ECM are also highly dynamic, and can influence stem cell differentiation pathways to a substantial degree. We previously discussed examples of using hydrogels to mimic these biochemical features, in this section we will highlight recent examples of tuning these factors dynamically. Many of the same chemistries used to tune mechanical properties over time can also be exploited to conjugate or cleave adhesion ligands or growth factors from 3D hydrogels. Kloxin et al. demonstrated that not only could photodegradation be used to soften PEG gels, but that cell adhesion peptides could also be removed from the gels by incorporating the photodegradable moiety adjacent to the RGDS peptide sequence [Kloxin et al., 2009]. Notably, MSCs cultured in gels where RGDS was removed after 10 days underwent enhanced chondrogenic differentiation and had increased GAG production compared to gels with persistent RGDS presentation or gels without RGDS at all. DeForest and Tirrell [2015] developed a method for reversible photopatterning of $3 \mathrm{D}$ gels by combining oxime-mediated ligation for photocoupling with a photodegradable o-nitrobenzyl ester to allow for incorporation and subsequent removal of a protein. This strategy was used to couple vitronectin into 3D gels with encapsulated MSCs. Cell spreading and osteogenic markers were observed when vitronectin was coupled, but were lost upon removal of vitronectin, with high spatial and temporal specificity.
Another strategy for dynamic incorporation of bioactive factors relies on the enzyme sortase A. The Griffith lab showed that EGF modified with the sortase ligation motif GGG could be coupled into PEG networks presenting the sortase substrate peptide sequence LPRTG, and subsequently removed by addition of the GGG motif only and sortase [Cambria et al., 2015] (Fig. 4a). DeForest and colleagues have very recently utilized sortase to apply photocleavable or photocoupling groups to the C-terminus of proteins, where modification is unlikely to disrupt bioactivity or protein structure [Shadish et al., 2019] (Fig. 4c). They again were used to reversibly photopattern 3D hydrogels with bioactive enzymes and growth factors, and even demonstrated subcellular spatial resolution in both patterning and cellular response. This group also used a sortase-mediated reaction to link proteins to stimuli responsive logic gates, allowing for release profiles governed by Boolean YES/AND/OR functions [Gawade et al., 2019]. Another approach to reversibly bind and remove adhesive ligands and proteins from hydrogels incorporates allyl sulfide functional groups within the hydrogel network to permit repeatable thiol-ene click reactions [Gandavarapu et al., 2014]. This strategy was used to reversibly couple and remove the adhesion peptide RGD, and later to reversibly pattern bioactive TGF- $B 1$ [Grim et al., 2018] (Fig. 4b). Development of technologies for dynamically controlled protein patterning in 3D environments has accelerated in recent years. These platforms must now be leveraged to achieve greater control of stem cell fate with spatiotemporally precise factor presentation.

\section{Conclusion}

As we have highlighted, much progress has been made recently in recapitulating essential aspects of the stem cell niche using hydrogels. In fact, hydrogels have been instrumental in uncovering a number of these important regulatory factors. Recently, the biological impact of matrix mechanical properties such as viscoelasticity and viscoplasticity have been brought to light [Chaudhuri et al., 2020]. While some data exists quantifying the viscoelastic/plastic behavior of adult tissues, a fuller mechanical characterization of the ECM in development and in stem cell niches is critically needed. Currently, the ability to tune these parameters in $3 \mathrm{D}$ hydrogels outpaces our knowledge of the properties of tissues, making it difficult to mimic native ECM behavior. Moving forward, there is still much work to be done to translate current hydrogel 
Fig. 4. Mimicking ECM biochemical dynamics with hydrogels. A Sortase A can be used to couple or cleave GGGtagged proteins into a 3D hydrogel network. B Allyl sulfide-modified PEG hydrogels were used to dynamically pattern and remove proteins with high spatiotemporal precision with 2-photon irradiation. C Site-specific protein modifications allow for minimal bioactivity changes and orthogonal photochemistries can be used for sequential patterning and release events. A Reproduced with permission according to ACSAuthorChoice [Cambria et al.]. Copyright 2015, American Chemical Society. B Reproduced with permission according to ACSAuthorChoice [Grim et al., 2018]. Copyright 2018, American Chemical Society. C Reprinted by permission from Springer Nature [Shadish et al., 2019], Copyright 2019.

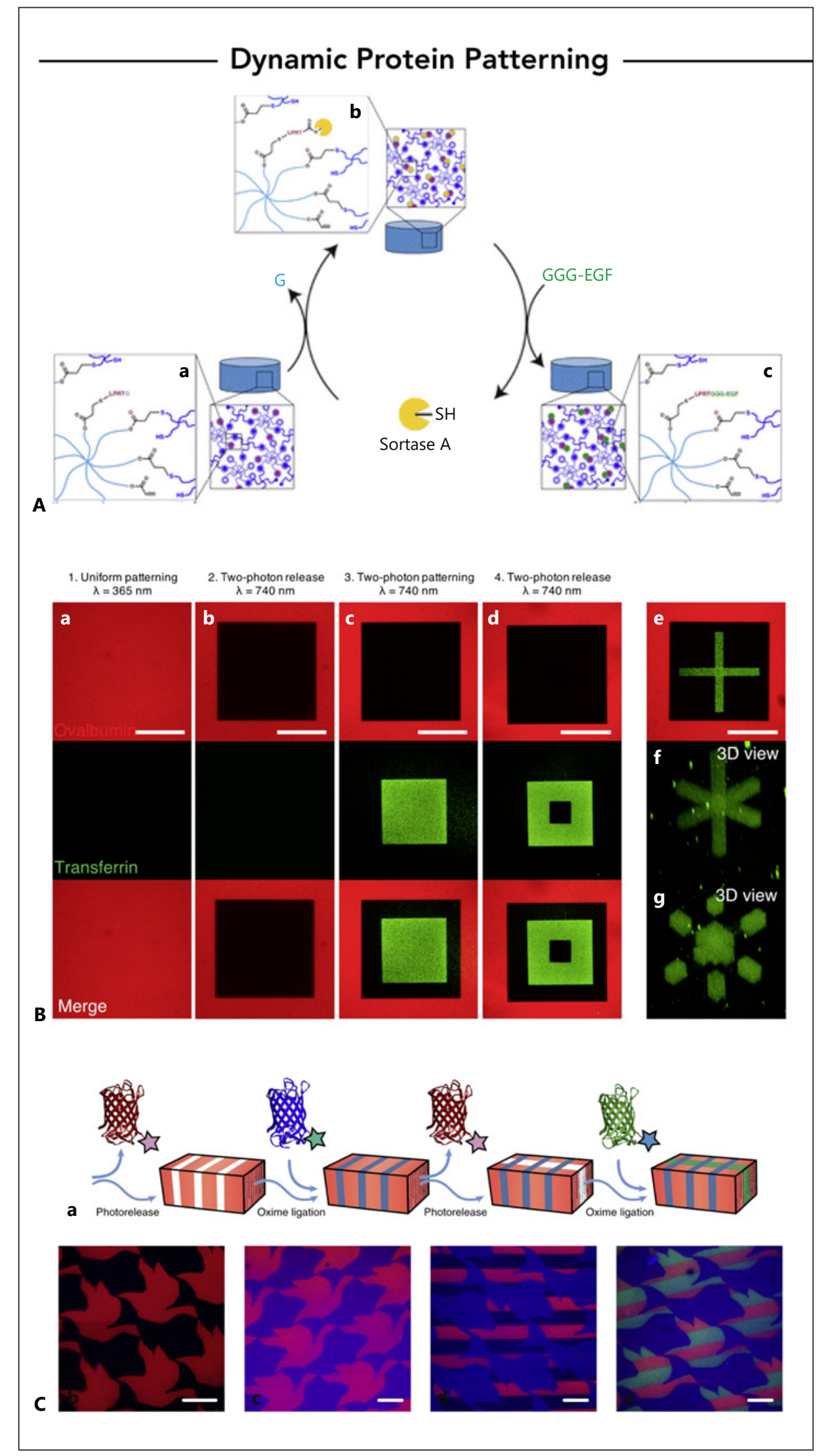

Cells Tissues Organs 2022;211:703-720 
platforms for cell culture to impactful tools for disease modeling and tissue regeneration. Continued progress must be made on the development of dynamically tunable hydrogels, including the ability to control multiple biophysical and biochemical properties simultaneously. Toward this end, one can imagine combinations of several biorthogonal conjugation and cleavage chemistries described above to permit alterations in mechanical properties alongside coupling of growth factors and exchange of adhesion peptides or proteins. However, the spatial, temporal, and compositional complexity of living tissue will always outpace our ability to model it with artificial microenvironments. Thus, one must consider how simple or complex a model system should be for a particular application, and an appropriate system should be selected or designed to meet the requirements of the question or objective at hand. Indeed, conventional 2D tissue culture methods have yielded tremendous insight into stem cell biology, exemplifying that even the simplest cell microenvironments are sufficient for many investigations. Other questions, for example the study of stem cell mechanical memory and its underlying molecular basis, inherently necessitate more complex platforms with dynamically tunable mechanical properties. Researchers engaged in the development of novel hydrogel cell culture platforms should also consider the ease of use of these systems, as simpler systems should be more widely adopted by the community.

Another avenue for balancing biology's immense complexity with the desire for sufficiently simple hydrogel platforms is to provide an appropriate microenvironmental context that allows cells to secrete factors and remodel their environment to provide these essential dynamic features themselves. Two independent groups have recently demonstrated that MSCs in 3D hydrogels begin depositing ECM proteins and proteoglycans within the first day of encapsulation, and that the secreted pericellular matrix can influence stem cell differentiation [Loebel et al., 2019b, 2020; Ferreira et al., 2018]. Designing materials to compensate for secreted ECM molecules, or even tailoring materials or directing cells to deposit ECM toward a desired effect would substantially enhance the ability to naturally guide stem cell fate. The generation of organoids from pluripotent stem cells is another example of allowing cellular self-organization to produce ECM and guide tissue development, and we have highlighted how hydrogels can be used to enhance organoid formation [Caiazzo et al., 2016; Gjorevski et al., 2016]. Very recently, Lutolf and colleagues have generated "mini-intestines" through matrix-guided cues to pro- mote the formation of perfusable, epithelial-lined tubes with the characteristic crypt and villus geometries from intestinal stem cells [Nikolaev et al., 2020]. Hydrogels are similarly utilized in a number of organ-on-a-chip platforms [Liu et al., 2019; Low et al., 2020], which should prove immensely valuable for disease modeling, drug screening, and could eventually lead to design parameters for larger scale functional tissue replacements. We anticipate continued acceleration in the design, control, and utilization of hydrogels for stem cell culture that will allow for both basic investigations into stem cell-microenvironment regulatory loops as well as translational impact through organoids, bioprinting, and organ-on-achip technologies.

\section{Acknowledgement}

R.S. gratefully acknowledges the Cells Tissues Organs Young Investigator Award and would like to thank members of the Stowers lab for helpful discussions.

\section{Conflict of Interest Statement}

The author has no conflicts of interest to declare.

\section{Funding Sources}

R.S. acknowledges support from the UCSB Academic Senate Faculty Research Grant.

\section{Author Contributions}

R.S. conceived and prepared this article.

References

Aisenbrey EA, Murphy WL. Synthetic alternatives to Matrigel. Nat Rev Mater. 2020;5(7): 539-51.

Allen SC, Widman JA, Datta A, Suggs LJ. Dynamic extracellular matrix stiffening induces a phenotypic transformation and a migratory shift in epithelial cells. Integr Biol (Camb). 2020;12(6):161-74.

Baker BM, Trappmann B, Wang WY, Sakar MS, Kim IL, Shenoy VB, et al. Cell-mediated fibre recruitment drives extracellular matrix mechanosensing in engineered fibrillar microenvironments. Nat Mater. 2015;14(12):1262-8.

Bao M, Xie J, Katoele N, Hu X, Wang B, Piruska A, et al. Cellular Volume and Matrix Stiffness Direct Stem Cell Behavior in a 3D Microniche. ACS Appl Mater Interfaces. 2019; 11(2):1754-9. 
Benoit DS, Anseth KS. Heparin functionalized PEG gels that modulate protein adsorption for hMSC adhesion and differentiation. Acta Biomater. 2005; 1(4):461-70.

Benoit DS, Durney AR, Anseth KS. The effect of heparin-functionalized PEG hydrogels on three-dimensional human mesenchymal stem cell osteogenic differentiation. Biomaterials. 2007;28(1):66-77.

Bentz H, Schroeder JA, Estridge TD. Improved local delivery of TGF-beta2 by binding to injectable fibrillar collagen via difunctional polyethylene glycol. J Biomed Mater Res. 1998;39(4):539-48.

Bertolo A, Arcolino F, Capossela S, Taddei AR, Baur M, Pötzel T, et al. Growth Factors CrossLinked to Collagen Microcarriers Promote Expansion and Chondrogenic Differentiation of Human Mesenchymal Stem Cells. Tissue Eng Part A. 2015;21(19-20):2618-28.

Bielajew BJ, Hu JC, Athanasiou KA. Collagen: quantification, biomechanics and role of minor subtypes in cartilage. Nat Rev Mater. 2020;5(10):730-47.

Bissell MJ, Aggeler J. Dynamic reciprocity: how do extracellular matrix and hormones direct gene expression?. Prog Clin Biol Res. 1987; 249:251-62.

Bissell MJ, Hall HG, Parry G. How does the extracellular matrix direct gene expression?. J Theor Biol. 1982;99(1):31-68.

Bosman FT, Stamenkovic I. Functional structure and composition of the extracellular matrix. J Pathol. 2003;200(4):423-8.

Brown TE, Carberry BJ, Worrell BT, Dudaryeva OY, McBride MK, Bowman CN, et al. Photopolymerized dynamic hydrogels with tunable viscoelastic properties through thioester exchange. Biomaterials. 2018;178:496-503.

Bryant SJ, Anseth KS. Controlling the spatial distribution of ECM components in degradable PEG hydrogels for tissue engineering cartilage. J Biomed Mater Res A. 2003;64(1): 70-9.

Burdick JA, Prestwich GD. Hyaluronic acid hydrogels for biomedical applications. Adv Mater Weinheim. 2011;23(12):H41-56.

Caiazzo M, Okawa Y, Ranga A, Piersigilli A, Tabata Y, Lutolf MP. Defined three-dimensional microenvironments boost induction of pluripotency. Nat Mater. 2016;15(3):344-52.

Caliari SR, Burdick JA. A practical guide to hydrogels for cell culture. Nat Methods. 2016; 13(5):405-14.

Caliari SR, Vega SL, Kwon M, Soulas EM, Burdick JA. Dimensionality and spreading influence MSC YAP/TAZ signaling in hydrogel environments. Biomaterials. 2016;103:314-23.

Cambria E, Renggli K, Ahrens CC, Cook CD, Kroll C, Krueger AT, et al. Covalent Modification of Synthetic Hydrogels with Bioactive Proteins via Sortase-Mediated Ligation. Biomacromolecules. 2015;16(8):2316-26.

Cameron AR, Frith JE, Cooper-White J. The influence of substrate creep on mesenchymal stem cell behaviour and phenotype. Biomaterials. 2011;32:5979-93.
Chang J, Pang EM, Adebowale K, Wisdom KM, Chaudhuri O. Increased Stiffness Inhibits Invadopodia Formation and Cell Migration in 3D. Biophys J. 2020;119(4):726-36.

Charrier EE, Pogoda K, Wells RG, Janmey PA. Control of cell morphology and differentiation by substrates with independently tunable elasticity and viscous dissipation. Nat Commun. 2018;9(1):449.

Chaudhuri O, Gu L, Klumpers D, Darnell M, Bencherif SA, Weaver JC, et al. Hydrogels with tunable stress relaxation regulate stem cell fate and activity. Nat Mater. 2016;15(3):32634.

Chaudhuri O, Cooper-White J, Janmey PA, Mooney DJ, Shenoy VB. Effects of extracellular matrix viscoelasticity on cellular behaviour. Nature. 2020;584(7822):535-46.

Chung C, Beecham M, Mauck RL, Burdick JA. The influence of degradation characteristics of hyaluronic acid hydrogels on in vitro neocartilage formation by mesenchymal stem cells. Biomaterials. 2009;30(26):4287-96.

Cruz-Acuña R, Quirós M, Farkas AE, Dedhia PH, Huang S, Siuda D, et al. Synthetic hydrogels for human intestinal organoid generation and colonic wound repair. Nat Cell Biol. 2017; 19(11):1326-35.

Cruz-Acuña R, Quirós M, Huang S, Siuda D, Spence JR, Nusrat A, et al. PEG-4MAL hydrogels for human organoid generation, culture, and in vivo delivery. Nat Protoc. 2018;13(9): 2102-19.

Davidson MD, Ban E, Schoonen ACM, Lee MH, D'Este M, Shenoy VB, et al. Mechanochemical Adhesion and Plasticity in Multifiber Hydrogel Networks. Adv Mater. 2020a;32(8): e1905719.

Davidson MD, Burdick JA, Wells RG. Engineered Biomaterial Platforms to Study Fibrosis. Adv Healthc Mater. 2020b;9(8):e1901682. n/a.

DeForest CA, Tirrell DA. A photoreversible protein-patterning approach for guiding stem cell fate in three-dimensional gels. Nat Mater. 2015;14(5):523-31.

Discher DE, Janmey P, Wang YL. Tissue Cells Feel and Respond to the Stiffness of Their Substrate. Science. 2005;310(5751):1139-43.

Discher DE, Mooney DJ, Zandstra PW. Growth Factors, Matrices, and Forces Combine and Control Stem Cells. Science. 2009;324(5935): 1673-7.

Engler AJ, Sen S, Sweeney HL, Discher DE. Matrix Elasticity Directs Stem Cell Lineage Specification. Cell. 2006;126(4):677-89.

Eroshenko N, Ramachandran R, Yadavalli VK, Rao RR. Effect of substrate stiffness on early human embryonic stem cell differentiation. J Biol Eng. 2013;7(1):7.

Ferreira SA, Motwani MS, Faull PA, Seymour AJ, Yu TTL, Enayati M, et al. Bi-directional cellpericellular matrix interactions direct stem cell fate. Nat Commun. 2018;9(1):4049.

Gandavarapu NR, Azagarsamy MA, Anseth KS. Photo-Click Living Strategy for Controlled, Reversible Exchange of Biochemical Ligands. Adv Mater Weinheim. 2014;26(16):2521-6.
Gattazzo F, Urciuolo A, Bonaldo P. Extracellular matrix: A dynamic microenvironment for stem cell niche. Biochim Biophys Acta. 2014; 1840(8):2506-19.

Gawade PM, Shadish JA, Badeau BA, DeForest CA. Logic-Based Delivery of Site-Specifically Modified Proteins from Environmentally Responsive Hydrogel Biomaterials. Adv Mater. 2019;31(33):e1902462.

Gefen A, Margulies SS. Are in vivo and in situ brain tissues mechanically similar?. J Biomech. 2004;37(9):1339-52.

Gilbert PM, Havenstrite KL, Magnusson KE, Sacco A, Leonardi NA, Kraft P, et al. Substrate Elasticity Regulates Skeletal Muscle Stem Cell Self-Renewal in Culture. Science. 2010; 329(5995):1078-81.

Gjorevski N, Sachs N, Manfrin A, Giger S, Bragina ME, Ordóñez-Morán P, et al. Designer matrices for intestinal stem cell and organoid culture. Nature. 2016;539(7630):560-4.

Grim JC, Brown TE, Aguado BA, Chapnick DA, Viert AL, Liu X, et al. A Reversible and Repeatable Thiol-Ene Bioconjugation for Dynamic Patterning of Signaling Proteins in Hydrogels. ACS Cent Sci. 2018;4(7):90916.

Guilak F, Cohen DM, Estes BT, Gimble JM, Liedtke W, Chen CS. Control of Stem Cell Fate by Physical Interactions with the Extracellular Matrix. Cell Stem Cell. 2009;5(1):1726.

Guo M, Pegoraro AF, Mao A, Zhou EH, Arany PR, Han Y, et al. Cell volume change through water efflux impacts cell stiffness and stem cell fate. Proc Natl Acad Sci USA. 2017; 114(41):E8618-27.

Guvendiren M, Burdick JA. Stiffening hydrogels to probe short- and long-term cellular responses to dynamic mechanics. Nat Commun. 2012;3:792.

Heino J. The collagen family members as cell adhesion proteins. BioEssays. 2007;29(10): 1001-10.

Heo SJ, Thorpe SD, Driscoll TP, Duncan RL, Lee DA, Mauck RL. Biophysical Regulation of Chromatin Architecture Instills a Mechanical Memory in Mesenchymal Stem Cells. Sci Rep. 2015;5:16895.

Heo SJ, Driscoll TP, Thorpe SD, Nerurkar NL, Baker BM, Yang MT, et al. Differentiation alters stem cell nuclear architecture, mechanics, and mechano-sensitivity. eLife. 2016a;5: e18207.

Heo SJ, Han WM, Szczesny SE, Cosgrove BD, Elliott DM, Lee DA, et al. Mechanically Induced Chromatin Condensation Requires Cellular Contractility in Mesenchymal Stem Cells. Biophys J. 2016b;111(4):864-74.

Hettiaratchi $\mathrm{MH}$, Guldberg RE, McDevitt TC. Biomaterial strategies for controlling stem cell fate via morphogen sequestration. J Mater Chem B. 2016;4(20):3464-81.

Highley CB, Rodell CB, Burdick JA. Direct 3D Printing of Shear-Thinning Hydrogels into Self-Healing Hydrogels. Adv Mater Weinheim. 2015;27(34):5075-9. 
Highley CB, Prestwich GD, Burdick JA. Recent advances in hyaluronic acid hydrogels for biomedical applications. Curr Opin Biotechnol. 2016;40:35-40.

Hörner M, Raute K, Hummel B, Madl J, Creusen G, Thomas OS, et al. Phytochrome-Based Extracellular Matrix with Reversibly Tunable Mechanical Properties. Adv Mater. 2019; 31(12):e1806727.

Huebsch N, Arany PR, Mao AS, Shvartsman D, Ali OA, Bencherif SA, et al. Harnessing traction-mediated manipulation of the cell/matrix interface to control stem-cell fate. Nat Mater. 2010;9(6):518-26.

Hughes CS, Postovit LM, Lajoie GA. Matrigel: A complex protein mixture required for optimal growth of cell culture. PROTEOMICS. 2010; 10(9):1886-90

Hui E, Gimeno KI, Guan G, Caliari SR. Spatiotemporal Control of Viscoelasticity in Phototunable Hyaluronic Acid Hydrogels. Biomacromolecules. 2019;20(11):4126-34.

Hushka EA, Yavitt FM, Brown TE, Dempsey PJ, Anseth KS. Relaxation of Extracellular Matrix Forces Directs Crypt Formation and Architecture in Intestinal Organoids. Adv Healthc Mater. 2020;9(8):e1901214.

Hussey GS, Dziki JL, Badylak SF. Extracellular matrix-based materials for regenerative medicine. Nat Rev Mater. 2018;3(7):159-73.

Hynes RO. The Extracellular Matrix: Not Just Pretty Fibrils. Science. 2009;326(5957):1216-

Ishihara J, Ishihara A, Fukunaga K, Sasaki K, White MJV, Briquez PS, et al. Laminin heparin-binding peptides bind to several growth factors and enhance diabetic wound healing. Nat Commun. 2018;9(1):2163

Jeon O, Song SJ, Lee K-J, Park MH, Lee S-H, Hahn SK, et al. Mechanical properties and degradation behaviors of hyaluronic acid hydrogels cross-linked at various cross-linking densities. Carbohydrate Polymers. 2007;70(3):251-7.

Jha AK, Mathur A, Svedlund FL, Ye J, Yeghiazarians Y, Healy KE. Molecular weight and concentration of heparin in hyaluronic acidbased matrices modulates growth factor retention kinetics and stem cell fate. J Control Release. 2015a;209:308-16.

Jha AK, Tharp KM, Ye J, Santiago-Ortiz JL, Jackson WM, Stahl A, et al. Enhanced survival and engraftment of transplanted stem cells using growth factor sequestering hydrogels. Biomaterials. 2015b;47:1-12.

Johnson MR, Boerckel JD, Dupont KM, Guldberg RE. Functional Restoration of Critically Sized Segmental Defects With Bone Morphogenetic Protein-2 and Heparin Treatment. Clin Orthop Relat Res. 2011;469(11):3111.

Kannus P. Structure of the tendon connective tissue. Scand J Med Sci Sports. 2000;10(6):31220.

Katsumi A, Orr AW, Tzima E, Schwartz MA. Integrins in Mechanotransduction. J Biol Chem. 2004;279(13):12001-4.

Khatiwala CB, Kim PD, Peyton SR, Putnam AJ. ECM Compliance Regulates Osteogenesis by
Influencing MAPK Signaling Downstream of RhoA and ROCK. J Bone Miner Res. 2009; 24(5):886-98.

Khetan S, Guvendiren M, Legant WR, Cohen DM, Chen CS, Burdick JA. Degradation-mediated cellular traction directs stem cell fate in covalently crosslinked three-dimensional hydrogels. Nat Mater. 2013;12(5):458-65.

Killaars AR, Grim JC, Walker CJ, Hushka EA, Brown TE, Anseth KS. Extended Exposure to Stiff Microenvironments Leads to Persistent Chromatin Remodeling in Human Mesenchymal Stem Cells. Adv Sci (Weinh). 2019; 6(3): 1801483

Killaars AR, Walker CJ, Anseth KS. Nuclear mechanosensing controls MSC osteogenic potential through HDAC epigenetic remodeling. Proc Natl Acad Sci USA. 2020;117(35): 21258-66.

Kleinman HK, Martin GR. Matrigel: Basement membrane matrix with biological activity. Semin Cancer Biol. 2005;15(5):378-86.

Kloxin AM, Kasko AM, Salinas CN, Anseth KS. Photodegradable Hydrogels for Dynamic Tuning of Physical and Chemical Properties. Science. 2009;324(5923):59-63.

Knaack S, Lode A, Hoyer B, Rösen-Wolff A, Gabrielyan A, Roeder I, et al. Heparin modification of a biomimetic bone matrix for controlled release of VEGF. J Biomed Mater Res A. 2014;102(10):3500-11.

Koch S, Yao C, Grieb G, Prével P, Noah EM, Steffens GC. Enhancing angiogenesis in collagen matrices by covalent incorporation of VEGF. J Mater Sci Mater Med. 2006;17(8):735-41.

Kyburz KA, Anseth KS. Synthetic Mimics of the Extracellular Matrix: How Simple is Complex Enough?. Ann Biomed Eng. 2015;43(3):489_ 500

Lang NR, Skodzek K, Hurst S, Mainka A, Steinwachs J, Schneider J, et al. Biphasic response of cell invasion to matrix stiffness in threedimensional biopolymer networks. Acta Biomater. 2015;13:61-7.

Lee HP, Gu L, Mooney DJ, Levenston ME, Chaudhuri O. Mechanical confinement regulates cartilage matrix formation by chondrocytes. Nat Mater. 2017;16(12):1243-51.

Lee HP, Stowers R, Chaudhuri O. Volume expansion and TRPV4 activation regulate stem cell fate in three-dimensional microenvironments. Nat Commun. 2019;10(1):529.

Leipzig ND, Shoichet MS. The effect of substrate stiffness on adult neural stem cell behavior. Biomaterials. 2009;30(36):6867-78.

Leivo I, Vaheri A, Timpl R, Wartiovaara J. Appearance and distribution of collagens and laminin in the early mouse embryo. Dev Biol. 1980;76(1):100-14

Li CX, Talele NP, Boo S, Koehler A, Knee-Walden E, Balestrini JL, et al. MicroRNA-21 preserves the fibrotic mechanical memory of mesenchymal stem cells. Nat Mater. 2017;16(3): 379-89.

Li Y, Tang CB, Kilian KA. Matrix Mechanics Influence Fibroblast-Myofibroblast Transition by Directing the Localization of Histone
Deacetylase 4. Cell Mol Bioeng. 2017;10(5): 405-15.

Liu F, Mih JD, Shea BS, Kho AT, Sharif AS, Tager AM, et al. Feedback amplification of fibrosis through matrix stiffening and COX-2 suppression. J Cell Biol. 2010;190(4):693-706.

Liu L, Shadish JA, Arakawa CK, Shi K, Davis J, DeForest CA. Cyclic Stiffness Modulation of Cell-Laden Protein-Polymer Hydrogels in Response to User-Specified Stimuli Including Light. Adv Biosys. 2018;2(12):1800240.

Liu H, Wang Y, Cui K, Guo Y, Zhang X, Qin J. Advances in Hydrogels in Organoids and Organson-a-Chip. Adv Mater. 2019;31(50):1902042.

Loebel C, Rodell CB, Chen MH, Burdick JA. Shear-thinning and self-healing hydrogels as injectable therapeutics and for 3D-printing. Nat Protoc. 2017;12(8):1521-41.

Loebel C, Ayoub A, Galarraga JH, Kossover O, Simaan-Yameen H, Seliktar D, et al. Tailoring supramolecular guest-host hydrogel viscoelasticity with covalent fibrinogen double networks. J Mater Chem B. 2019a;7(10):1753-60.

Loebel C, Mauck RL, Burdick JA. Local nascent protein deposition and remodelling guide mesenchymal stromal cell mechanosensing and fate in three-dimensional hydrogels. Nat Mater. 2019b;18(8):883-91.

Loebel C, Kwon MY, Wang C, Han L, Mauck RL, Burdick JA. Metabolic Labeling to Probe the Spatiotemporal Accumulation of Matrix at the Chondrocyte-Hydrogel Interface. Adv Funct Mater. 2020;30(44).

Lou YR, Kanninen L, Kuisma T, Niklander J, Noon LA, Burks D, et al. The Use of Nanofibrillar Cellulose Hydrogel As a Flexible Three-Dimensional Model to Culture $\mathrm{Hu}$ man Pluripotent Stem Cells. Stem Cells Dev. 2013;23(4):380-92.

Lou J, Stowers R, Nam S, Xia Y, Chaudhuri O. Stress relaxing hyaluronic acid-collagen hydrogels promote cell spreading, fiber remodeling, and focal adhesion formation in 3D cell culture. Biomaterials. 2018;154:213-22.

Low LA, Mummery C, Berridge BR, Austin CP, Tagle DA. Organs-on-chips: into the next decade. Nat Rev Drug Discov. 2020:1-17.

Lu P, Weaver VM, Werb Z. The extracellular matrix: A dynamic niche in cancer progression. J Cell Biol. 2012;196(4):395-406.

Lukashev ME, Werb Z. ECM signalling: orchestrating cell behaviour and misbehaviour. Trends Cell Biol. 1998;8(11):437-41.

Lutolf MP, Lauer-Fields JL, Schmoekel HG, Metters AT, Weber FE, Fields GB, et al. Synthetic matrix metalloproteinase-sensitive hydrogels for the conduction of tissue regeneration: Engineering cell-invasion characteristics. Proc Natl Acad Sci USA. 2003a;100(9):5413-8.

Lutolf MP, Raeber GP, Zisch AH, Tirelli N, Hubbell JA. Cell-Responsive Synthetic Hydrogels. Adv Mater. 2003b;15(11):888-92.

Mabry KM, Lawrence RL, Anseth KS. Dynamic stiffening of poly(ethylene glycol)-based hydrogels to direct valvular interstitial cell phenotype in a three-dimensional environment. Biomaterials. 2015;49:47-56. 
Madl CM, LeSavage BL, Dewi RE, Dinh CB, Stowers RS, Khariton M, et al. Maintenance of neural progenitor cell stemness in 3D hydrogels requires matrix remodelling. Nat Mater. 2017;16(12):1233-42.

Major LG, Holle AW, Young JL, Hepburn MS, Jeong K, Chin IL, et al. Volume Adaptation Controls Stem Cell Mechanotransduction. ACS Appl Mater Interfaces. 2019;11(49): 45520-30.

Marozas IA, Cooper-White JJ, Anseth KS. Photoinduced viscoelasticity in cytocompatible hydrogel substrates. New J Phys. 2019;21(4): 045004.

Martino MM, Hubbell JA. The 12th-14th type III repeats of fibronectin function as a highly promiscuous growth factor-binding domain. FASEB J. 2010;24(12):4711-21.

Martino MM, Tortelli F, Mochizuki M, Traub S, Ben-David D, Kuhn GA, et al. Engineering the Growth Factor Microenvironment with Fibronectin Domains to Promote Wound and Bone Tissue Healing. Sci Transl Med. 2011; 3(100): 100ra89.http: //dx.doi. org/10.1126/scitranslmed.3002614

McKinnon DD, Domaille DW, Brown TE, Kyburz KA, Kiyotake E, Cha JN, et al. Measuring cellular forces using bis-aliphatic hydrazone crosslinked stress-relaxing hydrogels. Soft Matter. 2014a;10(46):9230-6.

McKinnon DD, Domaille DW, Cha JN, Anseth KS. Biophysically Defined and Cytocompatible Covalently Adaptable Networks as Viscoelastic 3D Cell Culture Systems. Adv Mater Weinheim. 2014b;26(6):865-72.

Metters A, Anseth KS, Bowman CN. Fundamental studies of a novel, biodegradable PEG-b-PLA hydrogel. Polymer. 2000;41(11):3993-4004.

Miner JH. Yurchenco PD: Laminin Functions in Tissue Morphogenesis. Annu Rev Cell Dev Biol. 2004;20:255-84.

Nam S, Lee J, Brownfield DG, Chaudhuri O. Viscoplasticity Enables Mechanical Remodeling of Matrix by Cells. Biophys J. 2016;111(10): 2296-308.

Nam S, Stowers R, Lou J, Xia Y, Chaudhuri O. Varying PEG density to control stress relaxation in alginate-PEG hydrogels for $3 \mathrm{D}$ cell culture studies. Biomaterials. 2019;200:1524.

Nemec S, Kilian KA. Materials control of the epigenetics underlying cell plasticity. Nat Rev Mater. 2020:1-15.

Nikolaev M, Mitrofanova O, Broguiere N, Geraldo S, Dutta D, Tabata Y, et al. Homeostatic mini-intestines through scaffold-guided organoid morphogenesis. Nature. 2020; 585(7826):574-8.

Oftadeh R, Perez-Viloria M, Villa-Camacho JC, Vaziri A, Nazarian A. Biomechanics and Mechanobiology of Trabecular Bone: A Review. J Biomech Eng. 2015;137(1).

Orr AW, Helmke BP, Blackman BR, Schwartz MA. Mechanisms of Mechanotransduction. Dev Cell. 2006;10(1):11-20.

Ouyang L, Highley CB, Rodell CB, Sun W, Burdick JA. 3D Printing of Shear-Thinning
Hyaluronic Acid Hydrogels with Secondary Cross-Linking. ACS Biomater Sci Eng. 2016; 2(10): 1743-51.

Pantoliano MW, Horlick RA, Springer BA, Van Dyk DE, Tobery T, Wetmore DR, et al. Multivalent Ligand-Receptor Binding Interactions in the Fibroblast Growth Factor System Produce a Cooperative Growth Factor and Heparin Mechanism for Receptor Dimerization. Biochemistry. 1994;33(34):10229-48.

Park YD, Tirelli N, Hubbell JA. Photopolymerized hyaluronic acid-based hydrogels and interpenetrating networks. Biomaterials. 2003; 24(6):893-900.

Pelham RJ, Wang Y. Cell locomotion and focal adhesions are regulated by substrate flexibility. Proc Natl Acad Sci USA. 1997;94(25): 13661-5.

Perez Gonzalez N, Tao J, Rochman ND, Vig D, Chiu E, Wirtz D, et al. Cell tension and mechanical regulation of cell volume. Mol Biol Cell. 2018;29(21):0.

Prince E, Kumacheva E. Design and applications of man-made biomimetic fibrillar hydrogels. Nat Rev Mater. 2019;4(2):99-115.

Przybyla L, Lakins JN, Weaver VM. Tissue Mechanics Orchestrate Wnt-Dependent Human Embryonic Stem Cell Differentiation. Cell Stem Cell. 2016;19(4):462-75.

Rammensee S, Kang MS, Georgiou K, Kumar S, Schaffer DV. Dynamics of Mechanosensitive Neural Stem Cell Differentiation. Stem Cells. 2017;35(2):497-506

Rapp TL, DeForest CA. Visible Light-Responsive Dynamic Biomaterials: Going Deeper and Triggering More. Adv Healthc Mater. 2020; 9(7):e1901553.

Richardson B M, Walker C J, Macdougall L J, Hoye J W, Randolph M A, Bryant S J, et al. Viscoelasticity of hydrazone crosslinked poly(ethylene glycol) hydrogels directs chondrocyte morphology during mechanical deformation. Biomater Sci. 2020;8(14):3804-11.

Rodell CB, Kaminski AL, Burdick JA. Rational design of network properties in guest-host assembled and shear-thinning hyaluronic acid hydrogels. Biomacromolecules. 2013;14(11): 4125-34.

Rodell CB, MacArthur JW, Dorsey SM, Wade RJ, Wang LL, Woo YJ, et al. Shear-Thinning Supramolecular Hydrogels with Secondary Autonomous Covalent Crosslinking to Modulate Viscoelastic Properties In Vivo. Adv Funct Mater. 2015;25(4):636-44.

Rosales AM, Mabry KM, Nehls EM, Anseth KS. Photoresponsive Elastic Properties of Azobenzene-Containing Poly(ethylene-glycol)Based Hydrogels. Biomacromolecules. 2015; 16(3):798-806.

Rosales AM, Vega SL, DelRio FW, Burdick JA, Anseth KS. Hydrogels with Reversible Mechanics to Probe Dynamic Cell Microenvironments. Angew Chem Int Ed Engl. 2017; 56(40):12132-6.

Rozario T, DeSimone DW. The extracellular matrix in development and morphogenesis: A dynamic view. Dev Biol. 2010;341(1):126-40.
Saha K, Keung AJ, Irwin EF, Li Y, Little L, Schaffer DV, et al. Substrate Modulus Directs Neural Stem Cell Behavior. Biophys J. 2008;95(9): 4426-38.

Schwartz MA. Integrins and Extracellular Matrix in Mechanotransduction. Cold Spring Harb Perspect Biol. 2010;2(12):a005066.

Shadish JA, Benuska GM, DeForest CA. Bioactive site-specifically modified proteins for $4 \mathrm{D}$ patterning of gel biomaterials. Nat Mater. 2019; 18(9): 1005-14.

Stowers RS, Drinnan CT, Chung E, Suggs LJ. Mesenchymal stem cell response to TGF- $\beta 1$ in both $2 \mathrm{D}$ and $3 \mathrm{D}$ environments. Biomater Sci. 2013;1(8):860-9.

Stowers RS, Allen SC, Suggs LJ. Dynamic phototuning of 3D hydrogel stiffness. Proc Natl Acad Sci USA. 2015;112(7):1953-8.

Stowers RS, Shcherbina A, Israeli J, Gruber JJ, Chang J, Nam S, et al. Matrix stiffness induces a tumorigenic phenotype in mammary epithelium through changes in chromatin accessibility. Nat Biomed Eng. 2019;3(12):100919.

Tang S, Ma H, Tu HC, Wang HR, Lin PC, Anseth KS. Adaptable Fast Relaxing Boronate-Based Hydrogels for Probing Cell-Matrix Interactions. Adv Sci (Weinh). 2018;5(9):1800638.

Thiele J, Ma Y, Bruekers SM, Ma S, Huck WT. 25th Anniversary Article: Designer Hydrogels for Cell Cultures: A Materials Selection Guide. Adv Mater Weinheim. 2014;26(1): $125-47$.

Thompson LD, Pantoliano MW, Springer BA. Energetic characterization of the basic fibroblast growth factor-heparin interaction: identification of the heparin binding domain. Biochemistry. 1994;33(13):3831-40.

Tibbitt MW, Anseth KS. Hydrogels as Extracellular Matrix Mimics for 3D Cell Culture. Biotechnol Bioeng. 2009;103(4):655-63.

Varghese S, Hwang NS, Canver AC, Theprungsirikul P, Lin DW, Elisseeff J. Chondroitin sulfate based niches for chondrogenic differentiation of mesenchymal stem cells. Matrix Biol. 2008;27(1):12-21.

Wang YL, Pelham RJ. Preparation of a flexible, porous polyacrylamide substrate for mechanical studies of cultured cells. In:Methods in Enzymology. Academic Press; 1998. vol.298, p. 489-96

Wang C, Varshney RR, Wang DA. Therapeutic cell delivery and fate control in hydrogels and hydrogel hybrids. Adv Drug Deliv Rev. 2010; 62(7-8):699-710.

Wang H, Zhu D, Paul A, Cai L, Enejder A, Yang F, et al. Covalently Adaptable Elastin-Like Protein-Hyaluronic Acid (ELP-HA) Hybrid Hydrogels with Secondary Thermoresponsive Crosslinking for Injectable Stem Cell Delivery. Adv Funct Mater. 2017;27:1605609.

Wang LL, Highley CB, Yeh YC, Galarraga JH, Uman S, Burdick JA. Three-dimensional extrusion bioprinting of single- and double-network hydrogels containing dynamic covalent crosslinks. J Biomed Mater Res A. 2018; 106(4):865-75 
Watt FM, Huck WT. Role of the extracellular matrix in regulating stem cell fate. Nat Rev Mol Cell Biol. 2013;14(8):467-73.

Wisdom KM, Adebowale K, Chang J, Lee JY, Nam S, Desai R, et al. Matrix mechanical plasticity regulates cancer cell migration through confining microenvironments. Nat Commun. 2018;9(1):4144.

Wissink MJ, Beernink R, Scharenborg NM, Poot AA, Engbers GH, Beugeling T, et al . Endothelial cell seeding of (heparinized) collagen matrices: effects of bFGF pre-loading on proliferation (after low density seeding) and procoagulant factors. J Control Release. 2000; 67(2-3):141-55.

Wylie RG, Ahsan S, Aizawa Y, Maxwell KL, Morshead CM, et al. Spatially controlled simultaneous patterning of multiple growth factors in three-dimensional hydrogels. Nat Mater. 2011;10(10):799-806.
Xie K, Yang Y, Jiang H. Controlling Cellular Volume via Mechanical and Physical Properties of Substrate. Biophys J. 2018;114(3):675-87.

Xu R, Boudreau A, Bissell MJ. Tissue architecture and function: dynamic reciprocity via extraand intra-cellular matrices. Cancer Metastasis Rev. 2009;28(1-2):167-76.

Yang MT, Fu J, Wang YK, Desai RA, Chen CS. Assaying stem cell mechanobiology on microfabricated elastomeric substrates with geometrically modulated rigidity. Nat Protoc. 2011;6(2):187-213.

Yang C, Tibbitt MW, Basta L, Anseth KS. Mechanical memory and dosing influence stem cell fate. Nat Mater. 2014;13(6):645-52.

Yavitt FM, Brown TE, Hushka EA, Brown ME, Gjorevski N, Dempsey PJ, et al. The Effect of Thiol Structure on Allyl Sulfide Photodegradable Hydrogels and their Application as a Degradable Scaffold for Organoid Passaging. Adv Mater. 2020;32(30):e1905366.
Yoshikawa Y, Yasuike T, Yagi A, Yamada T. Transverse Elasticity of Myofibrils of Rabbit Skeletal Muscle Studied by Atomic Force Microscopy. Biochem Biophys Res Commun. 1999;256(1):13-9.

Young JL, Engler AJ. Hydrogels with time-dependent material properties enhance cardiomyocyte differentiation in vitro. Biomaterials. 2011;32(4):1002-9.

Zagris N. Extracellular matrix in development of the early embryo. Micron. 2001;32(4):427-38.

Zaman MH, Trapani LM, Sieminski AL, Siemeski A, Mackellar D, Gong H, et al. Migration of tumor cells in $3 \mathrm{D}$ matrices is governed by matrix stiffness along with cell-matrix adhesion and proteolysis. Proc Natl Acad Sci USA. 2006;103(29):10889-94.

Zustiak SP, Leach JB. Hydrolytically Degradable Poly(Ethylene Glycol) Hydrogel Scaffolds with Tunable Degradation and Mechanical Properties. Biomacromolecules. 2010;11(5):1348-57. 